\title{
De behandeling van blaaskanker vraagt om gecentraliseerde zorg
}

\author{
Jorg R. Oddens ${ }^{1} \cdot$ Joost L. Boormans ${ }^{2}$
}

Published online: 12 September 2017

(C) The Author(s) 2017. This article is an open access publication.

Samenvatting De kwaliteit van zorg voor blaaskankerpatiënten is niet in alle Nederlandse ziekenhuizen gelijk. Door in te zetten op samenwerking tussen ziekenhuizen, gericht op zorgpaden en uitkomsten van zorg, is het mogelijk om snel verbeteringen te realiseren. Aandacht voor patiëntgerelateerde uitkomsten is daarbij van wezenlijk belang.

Trefwoorden blaaskanker · kwaliteit van zorg . Nederlandse Kanker Registratie · patiëntgerelateerde uitkomstmaten

\section{Treatment of bladder cancer demands centralized hospital care}

\begin{abstract}
Quality of care for bladder cancer patients differs between Dutch hospitals. Improving the collaboration between hospitals, focussing on healthcare pathways and outcome measures will be helpful in establishing quick improvements. In this respect it is important to incorporate patient related outcome measures.
\end{abstract}

Keywords bladder cancer - quality of care $\cdot$ Netherland Cancer Registry $\cdot$ patient related outcome measures

dr. Jorg R. Oddens

j.oddens@jbz.nl

Jeroen Bosch Ziekenhuis, 's-Hertogenbosch, Nederland

2 Erasmus MC - Kanker Instituut, Rotterdam, Nederland

\section{Introductie}

Wat mag een patiënt, die mogelijk blaaskanker heeft, verwachten van de uroloog? Dat de patiënt terechtkomt bij iemand die de kennis in huis heeft om met doelgericht onderzoek vast te stellen of hij blaaskanker heeft. Dat de uroloog goed kan uitleggen wat dat betekent, welke behandelingen er zijn en waarom de patiënt voor welke behandeling in aanmerking komt en dat, als er meerdere behandelingsopties zijn, de uroloog ook dát uitlegt, met voldoende informatie over de voors en tegens, zodat de patiënt, als er een keuze is, weloverwogen kan meebeslissen. Tot zover geen verrassing.

Het zou voor de uitkomst van de behandeling geen verschil moeten maken in welk ziekenhuis die patiënt binnenstapt. En daar wringt het. Voor patiënten met een nietspierinvasief blaascarcinoom is in sommige ziekenhuizen verbeterde resectie mogelijk door de inzet van fotodynamische diagnostiek, de narrow band imaging, en in andere ziekenhuizen niet. Daarmee zou de recidiefkans kunnen verschillen [1], afhankelijk van het ziekenhuis waar je binnenkomt. Het is overigens al langer bekend dat er alleen al door de operateur verschillen zijn in uitkomsten van een TURT [2]. Bij het spierinvasief blaascarcinoom komt het in de huidige praktijk voor dat de patiënt in het ene ziekenhuis geadviseerd wordt direct een cystectomie te ondergaan en in het andere ziekenhuis neoadjuvante chemotherapie aangeboden krijgt [3], of dat in het ene ziekenhuis gezegd wordt dat minimaal invasieve chirurgie goed is en in het andere een open operatie wordt aangeboden. Dat in het ene ziekenhuis de helft van die patiënten een neoblaas krijgt en in het andere ziekenhuis bijna niemand. Ook wordt op sommige plaatsen (chemo)radiatietherapie of brachytherapie als behandelingsmogelijkheid voor het spierinvasief blaascarcinoom aangeboden en op andere plaatsen niet. 


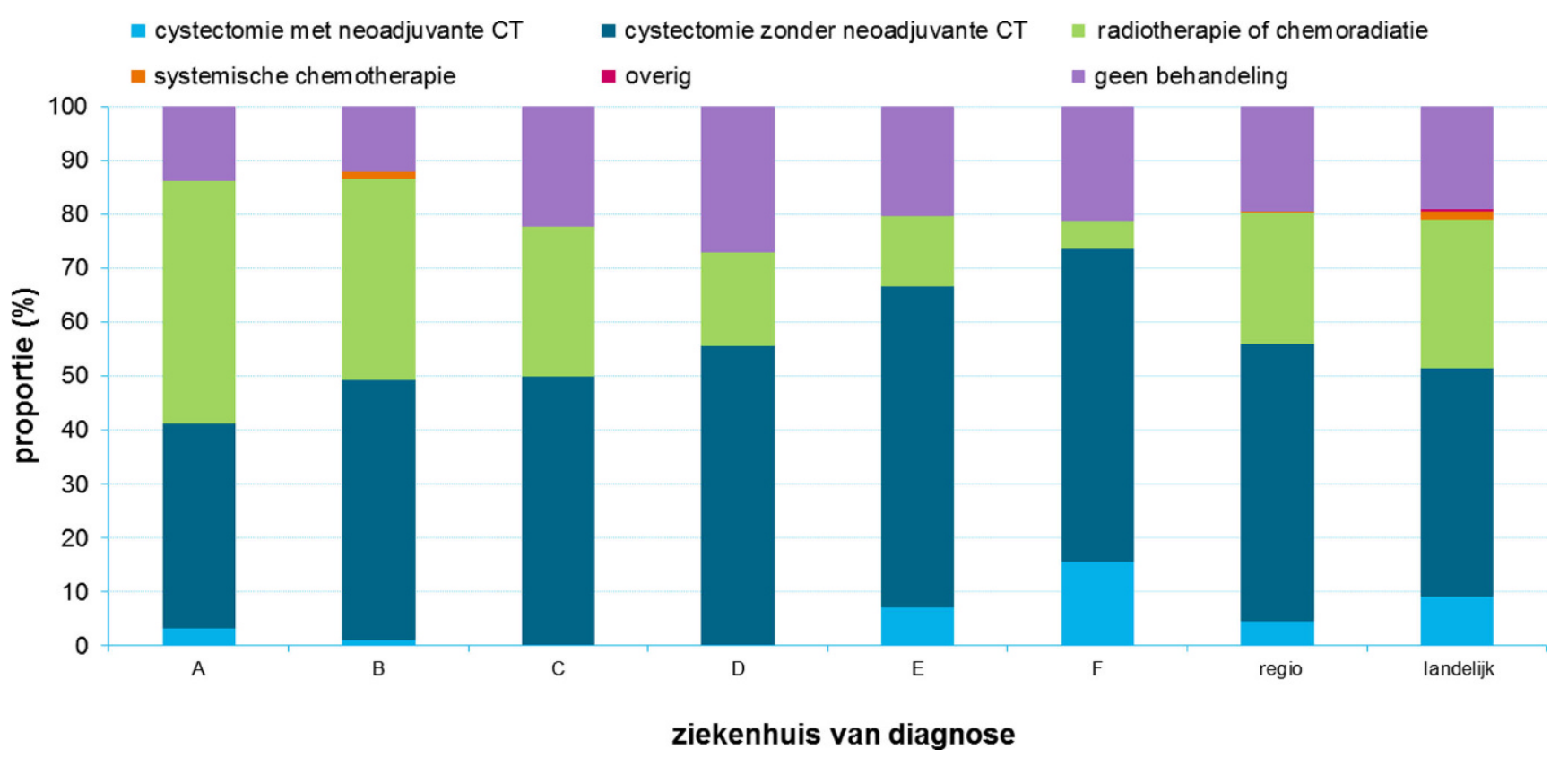

Figuur 1 Voorbeeld van regiorapportage blaaskanker van een fictieve regio, gebaseerd op werkelijke cijfers van acht ziekenhuizen. Behandeling van patiënten met cT2-cT4a cN0 cM0 urotheelcelcarcinoom in de blaas die zijn gediagnosticeerd in de jaren $2012 \mathrm{t} / \mathrm{m} 2014(n=228)$. Deze informatie heeft tot doel de discussie over de kwaliteit van zorg te faciliteren en is geen weergave van de verdeling van de markt (Bron: IKNL).

\section{De rol van de uroloog}

De uroloog is de poortwachter van de urologische tumoren. Het vaststellen van blaaskanker is voorbehouden aan de uroloog, die met weefseldiagnostiek kan vaststellen of en in welke mate blaaskanker aanwezig is. De verwachte werkwijze is gevat in richtlijnen en kwaliteitsnormen. Het IKNL heeft in diverse regio's per ziekenhuis laten zien dat er praktijkvariatie bestaat in de behandeling van het gelokaliseerd spierinvasief blaascarcinoom (operatief/ radiotherapeutisch/met of zonder (neoadjuvante) chemotherapie). Deze gegevens zijn door het IKNL in deze regio's besproken, maar zijn niet openbaar $[4,5]$. Fig. 1 laat verschillen in behandelingen zien van acht geanonimiseerde Nederlandse ziekenhuizen in een fictieve regio. Het is overigens zo dat de overlevingscijfers tussen Nederlandse ziekenhuizen niet statisch significant verschillend zijn.

In het streven naar 'optimale kwaliteit van urologische zorg', zoals de Nederlandse Vereniging voor Urologie (NVU) zich ten doel heeft gesteld in het Beleidsplan 2015-2020, is het nodig om initiatief te tonen, teneinde de huidige praktijk steeds te verbeteren. In de gesprekken met de vertegenwoordigers van de patiënten met blaaskanker en de verzekeraars komt het verzoek om te laten zien dat de urologen dit serieus nemen, regelmatig terug.

\section{Wat is belangrijk?}

Als de uitkomst van de zorg over het algemeen vrij goed is, hoe bepaal je dan op welke manier het beter moet? Als wetenschappelijk opgeleide beroepsgroep zijn we gewend om hiervoor een wetenschappelijke invalshoek te kiezen, maar er zijn daarnaast ook andere invalshoeken mogelijk, namelijk de maatschappelijke en de organisatorische.

\section{De wetenschappelijke invalshoek voor verbetering}

Er worden studies verricht naar de effectiviteit van de ene behandeling ten opzichte van andere behandelingen. Deze studies, meestal in de vorm van randomized controlled trials (RCT's) leveren wetenschappelijk bewijs op, dat wordt verwerkt in de richtlijnen. Het tot stand komen van dit bewijs kost jaren, waarna het implementeren in richtlijnen kan plaatsvinden. Het aanpassen van de praktijk kan daarna volgen. Het betreft een trage maar solide route voor verbetering van zorg. De praktijk is echter weerbarstiger: het volgen van richtlijnen voor de behandeling van blaaskanker, wat het best onderzocht is voor het niet-spierinvasief blaascarcinoom, blijkt lastig [6]. Of je als patiënt volgens de 'standaard' behandeld wordt, is dus niet vanzelfsprekend.

\section{De maatschappelijke invalshoek voor verbetering}

Vanuit het patiëntenperspectief is er vraag naar de uitkomsten van de geleverde zorg, die verder gaat dan ziektevrije periodes of overleving. De manier waarop aan het (wer- 
Tabel 1 Aantal bezoeken aan het ziekenhuis bij niet-gemetastaseerd invasief blaascarcinoom

\begin{tabular}{|c|c|}
\hline 1 & eerste bezoek vanwege bloed in urine \\
\hline 2 & cystoscopie (wellicht gecombineerd met eerste bezoek) \\
\hline 3 & CT-urinewegen \\
\hline 4 & preoperatief consult anesthesist \\
\hline 5 & opname voor TURT \\
\hline 6 & poli voor bespreken uitslag TURT en CT-urinewegen \\
\hline 7 & CT-thorax (of ander aanvullend onderzoek) \\
\hline 8 & $\begin{array}{l}\text { poli voor uitslag CT thorax en definitief behandelplan na } \\
\text { multidisciplinair overleg }\end{array}$ \\
\hline 9 & $\begin{array}{l}\text { voorbereidend bezoek stomaverpleegkundige en/of continen- } \\
\text { tieverpleegkundige (CIC; neoblaas) }\end{array}$ \\
\hline 10 & opnieuw preoperatief consult anesthesist \\
\hline 11 & opname voor cystectomie \\
\hline
\end{tabular}

$C I C$ continuous intermittent catheterisation, TURT transurethrale resectie.

kende) leven deelgenomen kan worden, speelt hierin een grote rol. Ook keuzebegeleiding voor behandelingen vallen binnen dit domein.

De uroloog als poortwachter en uitvoerder van behandelingen voor blaaskanker geeft hieraan nog relatief weinig aandacht, met als positieve uitzondering de ontwikkeling van keuzehulpen, ook voor bijvoorbeeld de keuze tussen een urinestoma en een neoblaas, waarvoor in het Radboudumc een ontwikkeltraject loopt. Het IKNL heeft onlangs een KWF-onderzoeksbeurs ontvangen voor de uitvoering van 'BlaaskankerZorg In Beeld' (BlaZIB). Dit BlaZIBonderzoek volgt de lijn van ProstaatkankerZorg In Beeld (ProZIB) en onderzoekt ook welke uitkomstmaten geschikt zijn als evaluatiemiddel voor kwaliteit van zorg, inclusief patiëntgerelateerde uitkomstmaten (PROM's). Uitkomsten van dit onderzoek laten evenwel nog wel enige tijd op zich wachten.

\section{De organisatorische invalshoek voor verbetering}

De organisatie van een urologische praktijk, al dan niet met een uitgewerkt zorgpad voor mensen die verwezen worden vanwege de verdenking op het hebben van een blaastumor, is grotendeels ingericht op basis van beschikbaarheid van mensen en middelen. Dat iemand met het vermoeden van een blaastumor snel wil weten waar hij aan toe is, is niet leidend in dit proces. Specifiek bij blaaskanker is het van belang om het gehele proces goed in beeld te hebben, juist vanwege de vele essentiële stappen die er een rol in spelen (tab. 1).

In de kwaliteitsnormen [7] van de NVU wordt gesteld dat een cystectomie binnen 12 weken na het stellen van de diagnose moet zijn uitgevoerd. Wat daarbij opvalt, is dat voor de uroloog het moment van het stellen van de diagnose samenvalt met het moment dat weefselonderzoek bekend is, terwijl de patiënt de diagnose terugrekent naar het moment dat hij voor het eerst bloed in de urine zag. De 12 weken als uiterste termijn is zelfs voor de Nederlandse situatie wetenschappelijk onderbouwd [8], maar het is invoelbaar dat de patiënt zich daar maar matig door laat geruststellen.

In een ziekenhuisorganisatie is het lastig om inzicht te hebben in de 'logistiek' van de patiëntenstroom: hoeveel patiënten die mogelijk blaaskanker hebben, wachten op dit moment op een afspraak? Hoeveel staan er op de wachtlijst voor een transurethrale resectie (TURT)? Is de CT-urinewegen al gemaakt als de TURT uitgevoerd wordt? Is de patiënt al besproken in het multidisciplinair overleg (MDO) als hij op de poli komt voor de uitslag van het weefselonderzoek? Dashboards die dit soort gegevens eenvoudig inzichtelijk maken, zitten niet standaard in de elektronische patiëntendossiers (EPD's).

Uit eigen ervaring puttend, gaf in het Jeroen Bosch Ziekenhuis het maken van een zorgpad, waarbij elk van deze stappen omschreven wordt, inclusief de personen die daarbij betrokken zijn, direct inzicht in de manier waarop dit proces was vormgegeven en leidde daardoor al direct tot verbeteracties. Bijvoorbeeld door het tegelijkertijd plannen van de operatiedatum en de poliafspraak na de TURT, in plaats van deze laatste te plannen bij ontslag na de operatie. Of de afspraak met de afdeling Radiologie dat, bij de indicatie blaastumor, de CT-scan ook daadwerkelijk binnen tien dagen gemaakt werd. Deze werkwijze werd in de oncologische samenwerking met het Radboudumc nog eens overgedaan, maar nu met de inzichten van twee grote maar verschillend georganiseerde ziekenhuizen. Het inzichtelijk maken van de zorgtrajecten en het transparant maken en delen van dit inzicht met anderen leidt zo tot verdere verbeteringen van het proces.

\section{De toekomst: hoe dragen we zorg voor een steeds verbeterende zorg voor blaaskanker?}

De urologen kunnen, door op verschillende manieren samen te werken, zichtbaar maken hoe (goed) de zorg nu is en welke maatregelen er worden genomen om de zorg te verbeteren. In de wijze van samenwerken zijn opnieuw verschillende manieren aan te geven.

\section{De wetenschappelijke manier van samenwerken}

Ziekenhuizen beschikken over een heleboel data. Door op een slimme manier in verschillende fasen van de behandeling punten te identificeren en vervolgens op grote schaal te verzamelen, wordt duidelijk hoe we samen blaaskanker behandelen. In de huidige praktijk is alleen de NVU kwaliteitsregistratie 'Spierinvasief Blaascarcinoom \& Cystectomie' actief: een karige afspiegeling van alle blaaskanker- 
Tabel 2 Blaaspoort randvoorwaarden

Doelgroep

- Patiënten met hoogrisico niet-spierinvasief blaascarcinoom, spierinvasief blaascarcinoom of gemetastaseerd blaascarcinoom

Team

- Oncologisch uroloog, radiotherapeut, medisch oncoloog, stoma- en continentieverpleegkundige, oncologieverpleegkundige, seksuoloog, radioloog, patholoog

Intake

- Bepaald dagdeel per week bij een van de ziekenhuizen in de regio.

- Patiënt kan binnen één week terecht.

- Counseling en triage door oncologisch uroloog.

- Standaard counseling door medisch oncoloog of radiotherapeut.

- Aansluitend aan gesprek met de uroloog volgt intake bij oncologieverpleegkundige.

Logistiek en infrastructuur

- Het tumormateriaal dat verwijderd is in het verwijzend ziekenhuis wordt door gespecialiseerd uropatholoog opnieuw beoordeeld.

- Herbeoordeling van verrichte radiologische onderzoeken uit verwijzend ziekenhuis.

- Laboratoriumonderzoek wordt standaard herhaald.

- Op indicatie nieuwe beeldvorming of cystoscopie (blaasspiegeling) dezelfde dag.

- Blaaskankerinformatiepakket wordt verstrekt.

- Seksuologische vragenlijsten worden verstrekt.

- Patiënt vult kwaliteit-van-levenvragenlijsten digitaal in, die aan het einde van de consulten door oncologieverpleegkundige met patiënt en mantelzorger worden besproken.

- Informatie omtrent urineafleidingen en (robotgeassisteerde) cystectomie wordt verstrekt.

Besluitvorming

- Alle patiënten worden dezelfde dag besproken in de multidisciplinaire tumorwerkgroep urologie die aansluitend aan het spreekuur plaatsvindt.

- Indien patiënt kandidaat is voor radicale chirurgie (verwijderen van de blaas), dan volgt een intake bij de stomaconsulent.

- Patiënten krijgen standaard een seksuologisch consult aangeboden.

- Indien patiënt voorafgaand aan chirurgie met chemotherapie behandeld zal worden, zal de internist-oncoloog de logistiek overnemen.

- Indien patiënt behandeld zal worden middels uitwendige radiotherapie, chemoradiotherapie of (partiële cystectomie) met brachytherapie, zal de radiotherapeut de logistiek overnemen; de follow-up is weer in handen van de uroloog.

- Alle patiënten worden geregistreerd in de landelijke database 'Spierinvasief Blaascarcinoom \& Cystectomie' van de Nederlandse Vereniging voor Urologie die gekoppeld is aan de zorgmonitor.

zorg en tevens niet transparant. Het BlaZIB-project is erop gericht een breder beeld te verkrijgen van de zorg rondom blaaskanker. Naar aanleiding daarvan hopen we een aantal zinnige parameters te destilleren, die de NVU eventueel blijvend kan (laten) monitoren. Als ook de PROM's hieruit vast komen te staan, is er direct zicht op de maatschappelijke gevolgen van blaaskankerzorg.

De nabije komst kent nog een uitdaging: het beschikbaar komen van nieuwe vormen van systeemtherapie (immunotherapie). Deze zullen in de palliatieve, maar ook in de adjuvante en neoadjuvante setting, een plaats krijgen bij het spierinvasief blaascarcinoom. Daarnaast wordt er onderzoek gedaan naar de inzet van deze nieuwe therapievormen bij niet-spierinvasief blaascarcinoom, waarbij ze als systemische behandeling worden toegevoegd aan instillaties. Als dit wordt gerealiseerd, zal een interactie kunnen ontstaan met de medisch oncoloog in een veld waarin de uroloog tot dusver de enige speler was.

\section{De organisatorische manier van samenwerken}

Om praktijkvariatie die voortkomt uit verschillen in inzicht en kennis, zo veel mogelijk te beperken, kan ervoor worden gekozen om groepen zorgaanbieders te creëren die gezamenlijk de indicaties bespreken voor diverse behande- lingen. De meest rudimentaire vorm van een dergelijke samenwerking is het MDO waarbij een ander ziekenhuis aansluit om desgevraagd advies te geven. In de praktijk is het organisatorisch echter niet altijd mogelijk om specifiek voor blaaskanker een expert aan te laten schuiven in een MDO waarin meerdere (urologische) tumortypen worden besproken.

Uitgebreider wordt het wanneer een groep ziekenhuizen specifiek de blaastumoren samen bespreekt, of - nog verdergaand - de patiënten met een spierinvasief blaascarcinoom gezamenlijk uitnodigt op een van de poliklinieken. Een voorbeeld van zo'n aanpak is de Rotterdamse Blaaspoort (tab. 2), waarbij alle patiënten met een invasief blaascarcinoom uit de Rotterdamse regio multidisciplinair gecounseld worden (deelnemende ziekenhuizen: Groene Hart Ziekenhuis, IJsselland Ziekenhuis, Sint Franciscus Gasthuis en Vlietland, Havenziekenhuis, Maasstad Ziekenhuis, Ikazia Ziekenhuis, Spijkenisse Medisch Centrum, Van Weel-Bethesda Ziekenhuis en Erasmus MC). Dit houdt in dat patiënten centraal worden besproken en beoordeeld, en op uniforme wijze, met behulp van een digitaal platform (de Zorgmonitor), data van de patiënt, inclusief ingevulde kwaliteit-van-levenvragenlijsten, worden verzameld en gekoppeld aan de NVU-kwaliteitsregistratie Cystectomie. 


\section{Discussie}

In de taak van de NVU om ook voor blaaskanker de aangeboden zorg steeds verder te verbeteren, is er ruimte voor het stimuleren van (regionale) samenwerking tussen zorgverleners. De manier van samenwerken kan variëren van het samen bespreken van zorgpaden tot het samen uitvoeren van zorg. Dataverzameling als onderdeel van elke vorm van samenwerking die is gericht op inzicht in alle facetten van de geleverde zorg, waarmee deze facetten, waar nodig, kunnen worden bijgestuurd, moet een integraal onderdeel zijn van dit proces. Regionale of landelijke afspraken over het aanbieden van specifieke onderdelen van de zorg bij blaaskanker, zoals neoadjuvante chemotherapie of chemoradiatie kunnen de praktijkvariatie helpen verminderen.

Het organiseren van een regionale bespreking voor alle blaaskankerpatiënten kan een bijdrage leveren aan het op elkaar afstemmen van dergelijke afspraken. Ook het aanbod om deel te nemen aan regionale of landelijke studies, bijvoorbeeld binnen het landelijke multidisciplinaire platform Dutch Uro-Oncology Studygroup (DUOS) kan zo worden bevorderd. Sommige hoogcomplexe behandelingen bundelen op één locatie kan drempelverlagend werken. De veronderstelling daarbij is dat een team sneller verbetert als er meerdere gelijksoortige behandelingen worden gedaan, waarbij ook de voor- en nazorg door het hogere volume aan kwaliteit kan winnen. Resultaten van een dergelijke aanpak openbaar maken, helpt mee om zowel de zorgaanbieders als de patiënten op de hoogte te houden van de effecten van deze ontwikkelingen.

\section{Conclusie}

Het streven naar een steeds verbeterende oncologische zorg voor blaaskanker is een taak die de urologen actief moeten blijven uitvoeren. Om aan elke patiënt de best passende zorg te kunnen bieden, is het noodzakelijk om te weten wat de urologen leveren en met welke uitkomsten. Individuele ziekenhuizen zijn voor dit alles veel minder slagvaardig dan groepen zorgaanbieders, waarbij landelijke of regionale afspraken en transparantie nodig zijn om dit te ondersteunen.

Open Access This article is distributed under the terms of the Creative Commons Attribution 4.0 International License (http:// creativecommons.org/licenses/by/4.0/), which permits unrestricted use, distribution, and reproduction in any medium, provided you give appropriate credit to the original author(s) and the source, provide a link to the Creative Commons license, and indicate if changes were made.

\section{Literatuur}

1. Mariappan P, Rai B, El-Mokadem I, et al. Real-life experience: early recurrence with Hexvix photodynamic diagnosis-assisted transurethral resection of bladder tumour vs good-quality white light TURBT in new non-muscle-invasive bladder cancer. Urology. 2015;86:327.

2. Brausi M, Collette L, Kurth K, et al. Variability in the recurrence rate at first follow-up cystoscopy after TUR in stage Ta T1 transitional cell carcinoma of the bladder: a combined analysis of seven EORTC studies. Eur Urol. 2002;41:523-31. May.

3. Hermans TJ, Fransen van de Putte EE, Horenblas S, et al. Perioperative treatment and radical cystectomy for bladder cancer - a population based trend analysis of 10,338 patients in the Netherlands. Eur J Cancer. 2016;54:18-26. Feb.

4. Regiorapportages geven impuls aan discussie over kwaliteit van zorg. Beschikbaar via: https://www.iknl.nl/over-iknl/nieuws/ nieuws-detail/2016/02/16/regiorapportages-geven-impuls-aandiscussie-over-kwaliteit-van-zorg. Geraadpleegd op 6 juli 2017.

5. Aben KKH, Verhoeven R, Vries A de. De Nederlandse Kankerregistratie; een schat aan informatie. Tijdschr Urol. 2017;7:40-6.

6. Rhijn BW van, Burger M. Bladder cancer: Low adherence to guidelines in non-muscle-invasive disease. Nat Rev Urol. 2016;13:570-1.

7. Bruins HM, Aben KK, Arends TJ, et al. The effect of the time interval between diagnosis of muscle-invasive bladder cancer and radical cystectomy on staging and survival: A Netherlands Cancer Registry analysis. Urol Oncol. 2016;34(4):166.e1-166.e6.

8. Nederlandse Vereniging voor Urologie. Kwaliteitsnormen blaascarcinoom NVU. 4e druk. Utrecht: NVU; 2017.

dr. Jorg R. Oddens uroloog

dr. Joost L. Boormans uroloog 